\title{
The Transtheoretical Model in Weight Management: Validation of the Processes of Change Questionnaire
}

\author{
Ana Andrés ${ }^{\mathrm{a}} \quad$ Carmina Saldaña $^{\mathrm{b}} \quad$ Juana Gómez-Benito ${ }^{\mathrm{a}}$ \\ a Department of Methodology for the Behavioural Sciences, \\ ${ }^{b}$ Department of Personality, Assessment and Psychological Treatment, University of Barcelona, Barcelona, Spain
}

\author{
Keywords \\ Overweight - Obesity management . \\ Psychological aspects
}

\section{Summary}

Objective: The processes of change implied in weight management remain unclear. The present study aimed to identify these processes by validating a questionnaire designed to assess processes of change (the P-Weight) in line with the transtheoretical model. The relationship of processes of change with stages of change and other external variables is also examined. Methods: Participants were 723 people from community and clinical settings in Barcelona. Their mean age was $32.07(S D=14.55)$ years; most of them were women $(75.0 \%)$, and their mean $\mathrm{BMI}$ was $26.47(\mathrm{SD}=8.52) \mathrm{kg} / \mathrm{m}^{2}$. They all completed the $\mathrm{P}$-Weight and the stages of change questionnaire (SWeight), both applied to weight management, as well as two subscales from the Eating Disorders Inventory-2 and Eating Attitudes Test-40 questionnaires about the concern with dieting. Results: A 34-item version of the PWeight was obtained by means of a refinement process. The principal components analysis applied to half of the sample identified four processes of change. A confirmatory factor analysis was then carried out with the other half of the sample, revealing that the model of four freely correlated first-order factors showed the best fit (GFI = 0.988, $\mathrm{AGFI}=0.986, \mathrm{NFI}=0.986$, and $\mathrm{SRMR}=0.0559)$. Corrected item-total correlations (0.322-0.865) and Cronbach's alpha coefficients $(0.781-0.960)$ were adequate. The relationship between the P-Weight and the S-Weight and the concern with dieting measures from other questionnaires supported the validity of the scale. Conclusion: The study identified processes of change involved in weight management and reports the adequate psy- chometric properties of the P-Weight. It also reveals the relationship between processes and stages of change and other external variables.

\section{Introduction}

Overweight and obesity have become an important public health problem involving many associated conditions, including type 2 diabetes, hypertension and cardiovascular disease [1]. In Spain, 55\% of the population can be classified as overweight or obese, which is a higher prevalence than that of other European countries [2], but lower than the rate found in other places such as the USA and the UK [3]. Guidelines for weight loss programmes suggest establishing a balanced nutrition and combining this with increased physical activity [4]. However, Bautista-Castaño et al. [5] noted that the majority of obese people do not continue with weight loss programmes, and only a few of those who do so actually lose weight.

Faced with this discouraging situation, several authors have pointed out that motivational techniques promote weight loss by increasing attendance at weight loss programmes [6-8]. In this regard, the transtheoretical model (TTM) [9] offers a theoretical framework that can be useful for assessing readiness to change and, therefore, for tailoring interventions according to the patient's motivation and preventing dropout in the context of weight management $[10,11]$.

The TTM proposes two interrelated dimensions for the adequate assessment of behavioural modification: stages of change and processes of change [12]. 'Stages of change' represent the temporal, motivational and constancy aspects of change [13]. When modifying their behaviour, individuals move through these stages of change, from pre-contemplation (PC) to maintenance (M). PC is the stage at which there is no

\section{KARGER \\ Fax +497614520714 \\ Information@Karger.de}

www.karger.com (c) 2011 S. Karger GmbH, Freiburg

$1662-4025 / 11 / 0046-0433 \$ 38.00 / 0$

Accessible online at:

www.karger.com/ofa
Ana Andrés

Department of Methodology for the Behavioural Sciences

University of Barcelona

Passeig Vall d'Hebron, 171, 08035 Barcelona, Spain

Tel. + 34 93-4031137, Fax -34021359

anaandres@ub.edu 
intention to change behaviour in the foreseeable future, while in the subsequent contemplation (C) stage people are aware that a problem exists and are seriously thinking about overcoming it. Preparation (Prep) is a stage that combines intention and some small behavioural changes, while action (A) is the stage in which individuals have modified their behaviour for less than 6 months. Finally, $\mathrm{M}$ is the stage in which people work to prevent relapse and consolidate the healthy behaviour [12]. While 'stages of change' focus on when people change, 'processes of change' refer to how people change and consist of overt and covert activities that individuals engage in when they attempt to modify problem behaviours [14]. Up to twelve processes of change have been defined in the literature [15], with ten of them receiving the most theoretical and empirical support [14] across a wide range of health problems [15]. Processes of change are differentially effective in certain stages of change [10]. Consequently, enhancing their use according to a person's readiness to change would facilitate that person's progress through the stages of change. In this context, the TTM posits that experiential processes are most useful during the earlier stages, whereas processes associated with behavioural components are most useful during the final stages of change [10]. The model also assumes that people at the earliest stage (PC) use processes significantly less often than do those at the later stages [16]; the use of processes increases linearly and peaks in a particular stage, before declining to the initial PC level, or somewhat higher if considering relapse prevention strategies [17].

The stages and processes of change model was initially validated in the context of smoking cessation $[18,19]$, and this research confirmed the existence of ten processes of change that were grouped into two general processes (experiential and behavioural). This model has also been shown to be valid in other fields, such as alcohol misuse [20, 21] and exercise [22, 23]. However, alternative models involving fewer processes have been found to be the most comprehensive in other fields [24-26]. In this regard, Horwath [27] and Povey et al. [28] have both questioned whether the processes of change originally defined by the TTM in the context of addictions would also be applicable to the field of weight management. At present, there is no consensus regarding the number of processes of change that are involved in weight control [27], since first- and second-order factor models considering between four and twelve processes have been proposed [29-32].

Several studies highlight the need for further research to confirm the model that was initially tested in smoking cessation [27, 33], since there is evidence that this model is not substantively meaningful in the acquisition of other healthy behaviours [22]. Similarly, the relationship between stages and processes of change remains unclear beyond the field of the addictions [27, 33], including the case of weight management $[30,31]$.

Consequently, and given the differences between the fields of addictions and weight management in relation to the acqui- sition of healthy behaviours [27, 34], more research is needed to generalise the stages and processes of change model to the latter field. Furthermore, questionnaires that aim to assess TTM constructs in the context of weight management are usually adapted from other instruments designed to assess stages and processes of change in addictive behaviours, which may cause problems for the model. Indeed, although weight management implies the inter-relationship of complex behaviours, the assessment of stages and processes of change in this field has usually been carried out through the separate assessment of specific dietary behaviours and exercise. As Horwath [27] asserts, the validation of the stages and processes model in relation to the acquisition of different healthy behaviours requires the application of appropriate methods. Therefore, having instruments specifically developed in the context of weight management to measure both dietary behaviour and exercise will provide a more accurate assessment of the TTM constructs.

The aims of the present study were: i) to identify the processes of change implied in weight management by validating the Spanish version of a processes of change questionnaire previously developed in the context of weight management (the P-Weight); ii) to analyse the reliability of the P-Weight questionnaire; iii) to assess the use of processes of change across stages of change in weight management; and iv) to assess the relationship between processes of change in weight management and external measures related to the concern with dieting

\section{Participants and Methods}

Questionnaire Development and Pilot Study

The P-Weight was previously developed [35] in line with the TTM. Using the Delphi method [36], a panel of 66 experts assessed the content of the 107 initial items that made up the P-Weight. Over three consecutive rounds these experts gave their opinion about which items should be included in the questionnaire until consensus was reached. A 63-item version of the questionnaire was finally obtained. A one-item algorithm with five distinct and mutually exclusive responses was designed to measure the stages of change as applied to weight management (S-Weight). Since this algorithm appears to have become the assessment method of choice $[37,38]$, participants were asked to choose the response that best corresponded to their current situation as regards losing weight. The S-Weight was likewise assessed by the panel of experts. Both the processes and stages of change questionnaires were simultaneously developed in English and Spanish. A more detailed description of the content validity analysis of these questionnaires is described elsewhere [35].

Once the P-Weight and the S-Weight had been developed, a pilot study was carried out to assess whether the items were understandable by the target population. Specifically, a convenience sample of 27 overweight and obese people from the community were asked to read the questionnaires and to assess whether the items were easy to understand. Written informed consent was obtained from all participants. Their mean age was $42.68(\mathrm{SD}=9.70)$ years, and $63.2 \%$ of them were women. The mean BMI of the sample was $28.82(\mathrm{SD}=3.35) \mathrm{kg} / \mathrm{m}^{2}$. A total of $37.0 \%$ of the sample comprised people from the area of San Francisco, CA (USA), who assessed the questionnaires in their English version, while the remaining $63.0 \%$ came from Barcelona (Spain), and who therefore assessed the 
Spanish version of the questionnaires. In the event that any item was not understandable, participants were asked to explain why. Almost all the items were rated as understandable, and any required changes in vocabulary were made to both the English and Spanish versions of the questionnaires.

\section{Participants}

Participants in the present study were 723 people drawn from the community and from primary care centres and hospitals in Barcelona. Questionnaires had initially been given to a sample of 1,032 people, and hence the participation rate was $70.9 \%$. Written informed consent was obtained from all participants, and the study was approved by the ethical committees of the medical centres where recruitment had taken place. Participants from the community $(\mathrm{n}=556)$ were non-randomly recruited from several settings, namely under- and post-graduate students, patients attending a psychotherapy service attached to the University of Barcelona, their relatives, and people from the general population. All participants were asked to complete the questionnaires and return them to the researchers. Participants from medical centres $(n=167)$ were patients enrolled in a hospital-based weight management programme and people attending routine appointments at a primary care centre. They were invited to participate in the study by their endocrinologist or by their family doctor or nurse. In the event that patients did not have enough time to complete the questionnaires at the centre, they were asked to fill them in at home and return them by post in the complementary envelope. Inclusion criteria were being over 18 years old and having a BMI $\geq 18.5 \mathrm{~kg} / \mathrm{m}^{2}$. Most of the participants were women $(75.0 \%)$, and the mean age was 32.07 $(\mathrm{SD}=14.55)$ years. BMI ranged widely $\left(18.51-59.88 \mathrm{~kg} / \mathrm{m}^{2}\right)$, the mean being $26.47(\mathrm{SD}=8.52) \mathrm{kg} / \mathrm{m}^{2}$. Overall, $83.83 \%$ of people from medical centres and $26.67 \%$ of people from the community sample reported being enrolled in a weight management programme. The analysis of educational level revealed that most of the participants had completed secondary $(54.1 \%)$ and higher $(39.9 \%)$ education. As regards income, $54.4 \%$ of the sample had an average income below the minimum wage (MW), while that of the remaining $27.8 \%$ ranged between 1 and 2 times the MW.

\section{Instruments}

Participants completed the Spanish version of the P-Weight and SWeight. As mentioned earlier, the P-Weight consisted of 63 items providing information about the processes of change defined by Prochaska and DiClemente [15]. These are the hypothesised processes that people use across the stages of change with the aim of managing weight.

The S-Weight consisted of five mutually exclusive items, among which participants had to choose in order to be allocated to one of the five stages of change [12]: PC, C, Prep, A, and M.

The 'drive for thinness' subscale of the Eating Disorder Inventory-2 (EDI-2) [39] and the 'diet' subscale of the Eating Attitudes Test-40 (EAT-40) [40] were applied to measure concerns about losing weight. Both questionnaires have been shown to have adequate psychometric properties in Spanish samples [40, 41].

\section{Data Analysis}

Descriptive and exploratory analyses and comparisons of means were performed using PASW Statistics 17 software, while AMOS 17.0 software (IBM, Armonk, NY, USA) was used for the confirmatory factor analyses (CFA).

Firstly, a descriptive analysis of items was performed to refine the PWeight. Several criteria were established to assess item appropriateness, and those items which did not meet all these criteria were deleted from the questionnaire. Items that fulfilled at least one of the following exclusion criteria were deleted from the questionnaire: missing data percentage $>5 \%$ [42], item-test correlations $<0.40$, maximum endorsement frequency $(\mathrm{MEF}) \geq 80 \%$ [43], standard deviation $<1.0$ [44], extreme values of skewness and/or kurtosis, and inter-item correlations $>0.70$ for some of the scale items [42].
Secondly, a cross-validation procedure was applied to the data in order to assess the internal structure of the questionnaire, as suggested by Floyd and Widaman [45]. Participants were randomly assigned to two groups: sample $1(\mathrm{n}=362)$ and sample $2(\mathrm{n}=361)$. Means were compared using Student's t tests, which revealed no differences between the two samples in terms of age or BMI. The chi-square test showed no statistical differences in the proportion of men and women in the two samples. Moreover, no differences were found in the two samples as regards the proportion of participants who were enrolled or not in a weight management programme. A principal components analysis (PCA) following Direct Oblimin rotation was applied to data obtained from sample 1. Factors were retained according to the scree test and the Kaiser-Guttman rule [46], which suggests keeping those factors with eigenvalues greater than 1.0. The factor structure of the questionnaire was then confirmed with a CFA applied to sample 2, using the covariance matrix. Before carrying out the CFA we tested whether the data were multivariate normal by means of Mardia's estimate for multivariate kurtosis [47]. According to Bentler [48], values above 5.0 for Mardia's normalised estimate are indicative of non-normal data. Since our data were multivariate non-normal, the unweighted least squares (ULS) estimation method was applied, and the following goodness-of-fit indices were obtained: chi-square test, goodness-of-fit index (GFI) and adjusted goodness-of-fit index (AGFI) [49], parsimony goodness-of-fit index (PGFI) [50], normed fit index (NFI) [51], and the standardised root mean square residual (SRMR) [49]. The chi-square difference test was applied to compare adjustment among nested models. The cut-off values to determine a good fit were equal or higher than 0.90 for GFI, AGFI and NFI [52], 0.60 for PGFI [50], and equal or lower than 0.08 for SRMR [53]. CFA was carried out in two steps, as recommended by Jackson et al. [52]. In a first step, the measurement model was tested aiming to confirm the suitability of items to their corresponding factor, according to the results obtained in the PCA. Then, in a second step, the structural model was tested in order to assess the possible relationships between latent variables. In this case, two alternative models were proposed, based on previous literature in this field. Thirdly, a reliability analysis was conducted for both samples by means of Cronbach's alpha and corrected item-total correlations, applying the criteria of Nunnally and Bernstein [54].

Analysis of variance (ANOVA) and Tukey post hoc comparisons were applied to assess the relationship between processes (taken as dependent variables) and stages of change (taken as the independent variable). Polynomial contrast analyses were conducted to analyse the trend in the use of processes of change across the stages of change.

Pearson's correlations were used to assess the relationship between the P-Weight and the measures of concerns with dieting.

Since the missing data rate was very low $(0.59 \%)$, any missing data items were replaced with the mean value that a given participant had obtained on the corresponding subscale, which is a widespread and reliable method [55]. However, it was only carried out when more than half the subscale items had been responded to. Missing imputation was conducted with the whole sample prior to carrying out the CFA.

\section{Results}

\section{Item Refinement}

Based on descriptive indicators, items were analysed to determine whether they were suitable to assess processes of change for weight management. In this phase of the analysis, responses of the whole sample $(n=723)$ were analysed. A total of 29 items were deleted according to the aforementioned criteria. It should be noted that none of the items were deleted due to the missing data percentage. A revised version of 
Table 1. Factor loadings of the 34-item questionnaire obtained in the principal components analysis

\begin{tabular}{|c|c|c|c|c|c|c|}
\hline & & \multirow[t]{2}{*}{ Communalities } & \multicolumn{4}{|c|}{ Factor loadings } \\
\hline & & & 1. EmR & 2. WMA & 3. EnR & 4. WCE \\
\hline Item 3 & I think I should eat food with less fat & 0.369 & 0.604 & & & \\
\hline Item 8 & Society's view of obese people affect me emotionally & 0.313 & 0.302 & & & \\
\hline Item 9 & I am worried about gaining more weight & 0.670 & 0.674 & & & \\
\hline Item 12 & Losing weight would make me improve to my relationships with others & 0.698 & 0.526 & & & \\
\hline Item 17 & Being overweight makes me feel bad & 0.778 & 0.527 & & & \\
\hline Item 18 & I feel guilty when I overeat & 0.644 & 0.685 & & & \\
\hline Item 19 & If I lost weight, I would feel better about myself & 0.772 & 0.814 & & & \\
\hline Item 20 & I'm not happy with my current weight & 0.678 & 0.709 & & & \\
\hline Item 22 & If I lost weight, I would be happier & 0.786 & 0.767 & & & \\
\hline Item 29 & I feel good when I am capable of controlling my eating habits & 0.486 & 0.541 & & & \\
\hline Item 33 & When I lose weight I feel proud of myself & 0.746 & 0.799 & & & \\
\hline Item 37 & $\begin{array}{l}\text { There is somebody who listens to me when I need to talk about my being } \\
\text { overweight }\end{array}$ & 0.468 & 0.457 & & & \\
\hline Item 41 & I am committed to losing weight & 0.683 & 0.547 & & & \\
\hline Item 4 & $\begin{array}{l}\text { I look for information about the types of food which could help me to } \\
\text { lose weight }\end{array}$ & 0.569 & & 0.390 & & \\
\hline Item 44 & I tell myself positive things to avoid overeating & 0.424 & & 0.492 & & \\
\hline Item 45 & When I really want to eat, I do activities to avoid it & 0.608 & & 0.420 & & \\
\hline Item 46 & I have learnt to control my appetite & 0.522 & & 0.683 & & \\
\hline Item 47 & I have learnt skills that reduce my appetite (e.g. relaxing) & 0.517 & & 0.650 & & \\
\hline Item 50 & I avoid buying high-calorie food & 0.473 & & 0.571 & & \\
\hline Item 62 & I prefer eating at home or cooking my own food to avoid overeating & 0.488 & & 0.486 & & \\
\hline Item 52 & I try to put food away so as to avoid nibbling & 0.576 & & & 0.426 & \\
\hline Item 53 & I try not to have food in sight & 0.632 & & & 0.536 & \\
\hline Item 54 & There are no snack foods in my fridge or cupboards & 0.433 & & & 0.561 & \\
\hline Item 61 & I avoid places where people eat a lot & 0.639 & & & 0.721 & \\
\hline Item 63 & When I am on a diet I avoid eating with people who I overeat with & 0.535 & & & 0.589 & \\
\hline Item 1 & I now realize I have a weight problem & 0.668 & & & & 0.645 \\
\hline Item 11 & My weight restricts my relationships & 0.608 & & & & 0.378 \\
\hline Item 13 & My current weight makes my daily life difficult & 0.738 & & & & 0.734 \\
\hline Item 14 & My family and friends are worried about my weight & 0.693 & & & & 0.864 \\
\hline Item 16 & Most of my health problems are due to my being overweight & 0.689 & & & & 0.817 \\
\hline Item 28 & $\begin{array}{l}\text { I am aware that there are more and more people who encourage me to } \\
\text { lose weight }\end{array}$ & 0.714 & & & & 0.790 \\
\hline Item 30 & My family and friends praise me for not overeating & 0.525 & & & & 0.543 \\
\hline Item 32 & My family and friends congratulate me when I manage to lose weight & 0.690 & & & & 0.641 \\
\hline Item 38 & People around me support me in trying to lose weight & 0.775 & & & & 0.719 \\
\hline \multicolumn{3}{|c|}{ Eigenvalues } & 14.86 & 2.74 & 1.67 & 1.33 \\
\hline
\end{tabular}

EmR = Emotional re-evaluation; WMA = weight management actions; EnR = environmental restructuring; WCE = weight consequences evaluation.

the questionnaire, consisting of 34 items, was obtained after this item refinement process.

The P-Weight and S-Weight in both the English and Spanish versions are available upon request.

\section{Internal Structure}

PCA was applied to data from sample $1(\mathrm{n}=362)$. KaiserMeyer-Olkin and Bartlett's tests indicated the adequacy of data $\left(\mathrm{KMO}=0.954, \chi^{2}(561, \mathrm{n}=362)=7,442.68 ; \mathrm{p}<0.0001\right)$. The PCA analysis revealed a four-factor solution. Communalities ranged between 0.313 and 0.786 (table 1 ), and the percentage of explained variance was $60.62 \%$. The corresponding factor loadings of these items were acceptable, since they reached 0.30 in all cases, as recommended by Floyd and Widaman [45]. In those cases where cross-loadings of similar weight were found, the fit of items to factors was decided according to the content of these items. Alternative models of five and six factors were tested, but none of them were interpretable. The four-factor solution led to a more suitable and interpretable version of the scale. The content analysis of factors revealed that items belonging to the same subscale were indeed measuring similar content. The resulting processes of change factors were labelled according to their specific content, obtaining the following processes of change for weight 
Table 2. Goodness-of-fit indices obtained in the confirmatory factor analyses

Table 3. Internal consistency analysis of the 34-item questionnaire in both samples

\begin{tabular}{lllllllll}
\hline & $\chi^{2}$ & d.f. & npar & GFI & AGFI & PGFI & NFI & SRMR \\
\hline Model 1 & $1,702.97$ & 521 & 112 & 0.988 & 0.986 & 0.865 & 0.986 & 0.0559 \\
Model 2a & $1,747.59$ & 523 & 115 & 0.987 & 0.986 & 0.868 & 0.985 & 0.0567 \\
Model 2b & $1,702.97$ & 522 & 117 & 0.988 & 0.986 & 0.866 & 0.986 & 0.0559 \\
\hline
\end{tabular}

$\chi^{2}=$ Chi-square test; d.f. $=$ degrees of freedom; npar = number of parameters; GFI = goodnessof-fit index; AGFI = adjusted goodness-of-fit index; PGFI = parsimony goodness-of-fit index; $\mathrm{NFI}=$ normed fit index; SRMR = standardised root mean square residual.

\begin{tabular}{|c|c|c|c|c|c|c|c|}
\hline & \multirow{2}{*}{$\begin{array}{l}\text { Number of } \\
\text { items }\end{array}$} & \multicolumn{3}{|c|}{ Sample $1(n=362)$} & \multicolumn{3}{|c|}{ Sample $2(n=361)$} \\
\hline & & $\alpha$ & $\begin{array}{l}\text { I-T corr } \\
\text { (range) }\end{array}$ & $\begin{array}{l}\text { I-T corr } \\
\text { (mean) }\end{array}$ & $\alpha$ & $\begin{array}{l}\text { I-T corr } \\
\text { (range) }\end{array}$ & $\begin{array}{l}\begin{array}{l}\text { I-T corr } \\
\text { (mean) }\end{array}\end{array}$ \\
\hline 1. EmR & 13 & 0.934 & $0.504-0.838$ & 0.693 & 0.928 & $0.322-0.824$ & 0.674 \\
\hline 2. WMA & 7 & 0.840 & $0.547-0.660$ & 0.595 & 0.806 & $0.496-0.617$ & 0.544 \\
\hline 3. EnR & 5 & 0.803 & $0.497-0.682$ & 0.589 & 0.781 & $0.442-0.632$ & 0.557 \\
\hline 4. WCE & 9 & 0.928 & $0.609-0.795$ & 0.738 & 0.938 & $0.674-0.865$ & 0.768 \\
\hline Total & 34 & 0.960 & $0.438-0.769$ & 0.627 & 0.960 & $0.342-0.779$ & 0.629 \\
\hline
\end{tabular}

I-T corr $=$ Item-total correlations; $\mathrm{EmR}=$ emotional re-evaluation; $\mathrm{WMA}=$ weight management actions; EnR = environmental restructuring; $\mathrm{WCE}$ = weight consequences evaluation. management: emotional re-evaluation (EmR, 13 items), weight management actions (WMA, 7 items), environmental restructuring (EnR, 5 items) and weight consequences evaluation (WCE, 9 items).

A CFA was then carried out to test the four-factor structure previously obtained. Sample $2(\mathrm{n}=361)$ was used for this analysis and the list-wise deletion method was applied $(\mathrm{n}=360)$. The assessment of multivariate normality revealed that the data did not fit multivariate normality, since Mardia's estimate for multivariate kurtosis was 50.07.

Model 1. The measurement model consisted of four freelycorrelated first-order factors in which items loaded according to the results found in the PCA, showing a good fit of data to this 34-item and four-factor model (table 2). Standardised regression weights ranged from 0.394 to 0.862 , while correlations between factors were between 0.704 and 0.860 . Supported by studies in which second-order factors were found to show the best fit [18-23, 31], two alternative models were tested in the second step of this analysis, which consisted in testing the structural model of the processes of change in weight management.

Model 2a. This model consisted of four first-order factors gathered under a general second-order factor measuring the general processes of change. Goodness-of-fit indices also showed an adequate fit of the data to this model (table 2). Standardised regression weights ranged from 0.798 to 0.946 .

Model 2b. A model involving two second-order factors was also tested. This was based on the hypothesis that the scores obtained in the processes of change subscales could be explained by the existence of two higher-order factors: experiential and behavioural. Consequently, factors 1 (EmR) and 4 (WCE) were gathered under the experiential process, whereas factors 2 (WMA) and 3 (EnR) were allocated to the behavioural process. Second-order processes were allowed to correlate. Goodness-of-fit indices are shown in table 2. Standardised regression weights ranged from 0.904 to 0.952 in the experiential process, and from 0.846 to 0.929 in the behavioural one. The correlation between the two higher-order processes was 0.920 .

Models were compared by applying the chi-square difference test to these three nested models. Model 1 showed a better fit compared to model 2a $\left(\Delta \chi^{2}(2)=44,631 ; \mathrm{p}<0.001\right)$, but no differences with respect to model $2 \mathrm{~b}\left(\Delta \chi^{2}(1)=0.002 ; \mathrm{p}=\right.$ 0.96). Although model $2 \mathrm{~b}$ showed a better fit to the data than did model 2a $\left(\Delta \chi^{2}(1)=44,629 ; \mathrm{p}<0.001\right)$, we considered it to be unfeasible due to the high correlation between the secondorder factors, $r=0.920$. As Brown [56] asserts, factor intercorrelations above 0.80 or 0.85 suggest that a more parsimonious solution can be obtained, since such values indicate poor discriminant validity. Consequently, the most parsimonious model of four freely correlated first-order factors (Model 1) best represented the structure of these data. Four scores corresponding to the four processes of change found in this analysis can therefore be obtained from this questionnaire. The path diagram representing this structure and standardised factor loadings and factor co-variances are shown in figure 1.

\section{Internal Consistency}

Cronbach's alpha coefficients and corrected item-total correlations were then calculated in both samples 1 and 2. Cronbach's alpha reached acceptable values, ranging from 0.803 to 0.934 for the different factors in sample 1 , and from 0.781 to 
Fig. 1. Path diagram representing the four first-order factors model for processes of change in weight management.

$\mathrm{EmR}=$ Emotional re-evaluation; $\mathrm{WMA}=$ weight management actions; EnR = environmental restructuring; $\mathrm{WCE}=$ weight consequences evaluation.

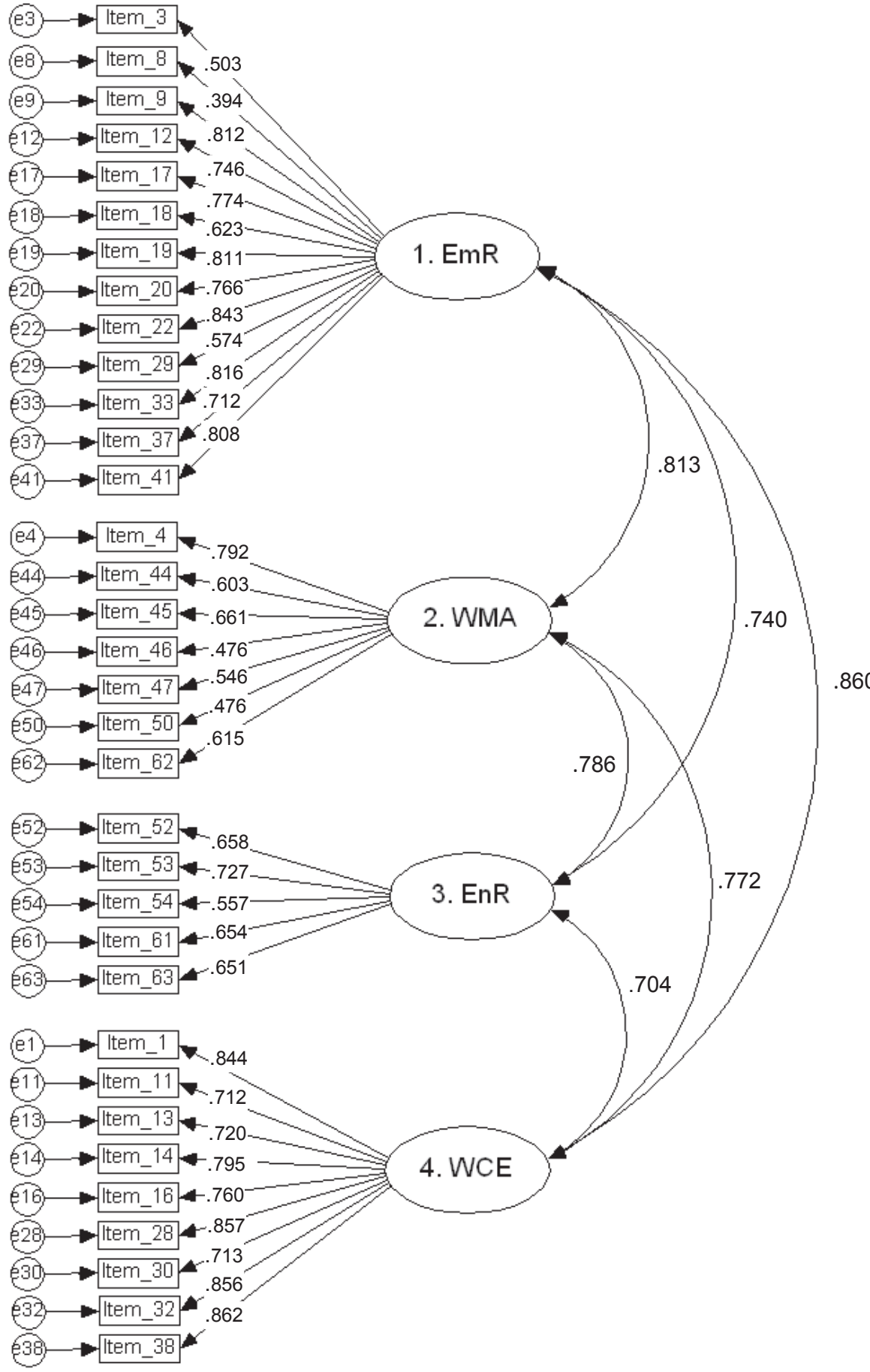

0.938 in sample 2 (table 3 ). All items contributed to the internal consistency of their subscale. Internal consistency was excellent when considering the whole scale (0.960). Corrected item-total correlations were also acceptable in both samples, ranging from 0.322 to 0.865 .

\section{Relationship between Processes and Stages of Change}

Since processes of change are attitudes and behaviours that facilitate a person's progress across the stages of change towards acquisition of a healthy behaviour, it is important to analyse the relationship between these two measures.
Scores for each of the four processes of change were calculated in the whole sample $(\mathrm{n}=723)$ by summing the scores obtained on items belonging to the same subscale. None of the items were reverse scored. In order to make scores from the different subscales comparable, these scores were transformed onto a scale from 0 to 100 ( 0 reflecting no use of a given process of change and 100 being full use of that process). The ANOVA revealed statistically significant differences for the use of processes across stages of change, as shown in table 4, while Cohen's $f$ indicated large effect sizes in all cases. Tukey post hoc comparisons showed that in the PC stage all processes were used less 
Table 4. Analysis of variance and post hoc comparisons of processes of change scores across stages of change

\begin{tabular}{|c|c|c|c|c|c|c|c|c|}
\hline & $\begin{array}{l}\mathrm{PC}, \\
\text { mean }(\mathrm{SD})\end{array}$ & $\begin{array}{l}\mathrm{C}, \\
\text { mean }(\mathrm{SD})\end{array}$ & $\begin{array}{l}\text { Prep, } \\
\text { mean (SD) }\end{array}$ & $\begin{array}{l}\mathrm{A}, \\
\text { mean }(\mathrm{SD})\end{array}$ & $\begin{array}{l}\text { M, } \\
\text { mean (SD) }\end{array}$ & $\mathrm{F}(4,706)$ & $\mathrm{f}$ & Tukey comparisons \\
\hline 1. EmR & $\begin{array}{l}24.65 \\
(15.68)\end{array}$ & $\begin{array}{l}57.03 \\
(17.98)\end{array}$ & $\begin{array}{l}65.06 \\
(16.76)\end{array}$ & $\begin{array}{l}67.52 \\
(16.02)\end{array}$ & $\begin{array}{l}58.63 \\
(22.27)\end{array}$ & $184.85 * *$ & 0.87 & $\begin{array}{l}\mathrm{PC}<\mathrm{C}^{* * * *}, \operatorname{Prep}^{* * *}, \mathrm{~A}^{* * *}, \mathrm{M}^{* * *} \\
\mathrm{C}<\mathrm{A}^{* * * *} \\
\mathrm{M}<\mathrm{A}^{* * *}\end{array}$ \\
\hline 2. WMA & $\begin{array}{l}22.02 \\
(17.58)\end{array}$ & $\begin{array}{l}36.05 \\
(15.86)\end{array}$ & $\begin{array}{l}38.75 \\
(16.40)\end{array}$ & $\begin{array}{l}52.89 \\
(15.27)\end{array}$ & $\begin{array}{l}49.78 \\
(20.84)\end{array}$ & $93.92 * *$ & 0.62 & $\begin{array}{l}\mathrm{PC}<\mathrm{C}^{* * *}, \operatorname{Prep} \mathrm{P}^{* * *}, \mathrm{~A}^{* * *}, \mathrm{M}^{* * *} \\
\mathrm{C}<\mathrm{A}^{*}, \mathrm{M}^{* * *} \\
\operatorname{Prep}<\mathrm{A}^{* * *}, \mathrm{M}^{* *}\end{array}$ \\
\hline 3. EnR & $\begin{array}{l}13.22 \\
(14.47)\end{array}$ & $\begin{array}{l}26.87 \\
(18.02)\end{array}$ & $\begin{array}{l}27.83 \\
(20.77)\end{array}$ & $\begin{array}{l}36.49 \\
(20.09)\end{array}$ & $\begin{array}{l}33.78 \\
(23.45)\end{array}$ & $47.15^{* *}$ & 0.43 & $\begin{array}{l}\mathrm{PC}<\mathrm{C}^{* * *}, \text { Prep } * * *, \mathrm{~A}^{* * *}, \mathrm{M}^{* * *} \\
\mathrm{C}<\mathrm{A}^{* *}, \mathrm{M}^{*} \\
\operatorname{Prep}<\mathrm{A}^{*}\end{array}$ \\
\hline 4. WCE & $\begin{array}{l}6.71 \\
(10.98)\end{array}$ & $\begin{array}{l}29.15 \\
(23.79)\end{array}$ & $\begin{array}{l}34.64 \\
(28.33)\end{array}$ & $\begin{array}{l}45.45 \\
(24.92)\end{array}$ & $\begin{array}{l}36.55 \\
(27.58)\end{array}$ & $90.44 * *$ & 0.60 & $\begin{array}{l}\mathrm{PC}<\mathrm{C}^{* * *}, \operatorname{Prep} \mathrm{p}^{* * *}, \mathrm{~A}^{* * *}, \mathrm{M}^{* * *} \\
\mathrm{C}<\mathrm{A}^{* * *}, \mathrm{M}^{*} \\
\operatorname{Prep}<\mathrm{A}^{*} \\
\mathrm{M}<\mathrm{A}^{*}\end{array}$ \\
\hline
\end{tabular}

EmR = Emotional re-evaluation; WMA = weight management actions; EnR = environmental restructuring; WCE = weight consequences evaluation; $\mathrm{PC}=$ pre-contemplation; $\mathrm{C}=$ contemplation; Prep = preparation; $\mathrm{A}=$ action; $\mathrm{M}=$ maintenance.

$* \mathrm{p}<0.05, * * \mathrm{p}<0.01, * * * \mathrm{p}<0.001$.

Fig. 2. Scores obtained on the processes of change subscales across the stages of change. EmR = Emotional re-evaluation; WMA = weight management actions; EnR = environmental restructuring; $\mathrm{WCE}=$ weight consequences evaluation; $\mathrm{PC}=$ pre-contemplation; $\mathrm{C}=$ contemplation; Prep = preparation; $\mathrm{A}=$ action; $\mathrm{M}=$ maintenance.

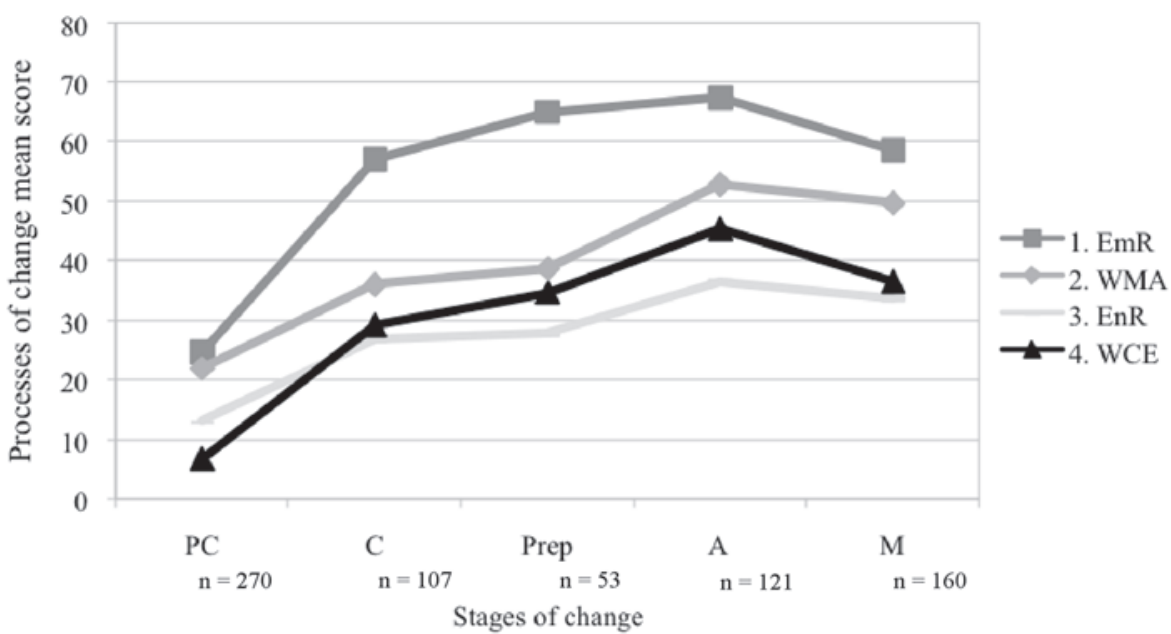

Table 5. Pearson's correlations between processes of change and the concern with dieting

\begin{tabular}{lcccc}
\hline & EmR & WMA & EnR & WCE \\
\hline Drive for thinness (EDI-2) & 0.737 & 0.560 & 0.555 & 0.643 \\
Diet (EAT-40) & 0.669 & 0.597 & 0.561 & 0.623 \\
\hline
\end{tabular}

EDI-2 = Eating Disorder Inventory-2; EAT-40 = Eating Attitudes Test-40; EmR = emotional re-evaluation; WMA = weight management actions; $\mathrm{EnR}$ = environmental restructuring; $\mathrm{WCE}=$ weight consequences evaluation.

All correlations are significant at $\mathrm{p}<0.0001$.

than in later stages. This was similar to the pattern of scores obtained in $\mathrm{C}$, which were lower than those obtained in $\mathrm{A}$ (for EmR subscale), as in the comparison between A and M (for subscales WMA, EnR and WCE) (fig. 2). It should be noted that the use of processes of change remains stable between the A and $\mathrm{M}$ stages, with higher scores being observed in A compared to $\mathrm{M}$ for some processes (on the EmR and WCE subscales). Polynomial contrast analyses revealed a quadratic trend in the use of every process of change across the stages $(\mathrm{p}<0.0001)$.

\section{Relationship of Processes of Change with Other Variables}

The four subscales of the P-Weight were correlated with other external variables measuring concern with dieting in the whole sample $(\mathrm{n}=723)$. Specifically, they were correlated with the 'drive for thinness' subscale of the EDI-2 and with the 'diet' subscale of the EAT-40 questionnaire, as shown in table 5. Pearson's correlation coefficient was statistically significant $(\mathrm{p}<0.0001)$ between the four processes of change subscales and both the 'drive for thinness' and 'diet' subscales. 


\section{Discussion}

The TTM has been widely used in order to target interventions [57], since it is a powerful tool in relation to both the targeting of resources and attempts to persuade individuals to change their behaviours [58]. However, a consensus has yet to be reached about the processes of change involved in weight management. Furthermore, as Bulley et al. [38] warn, careful consideration should be given to the accuracy of measures based on the TTM. To date, TTM-based questionnaires used in weight management interventions have been adapted from other behaviours such as smoking cessation, and, as already mentioned, more evidence is needed to confirm that this model is substantively meaningful in the weight management setting. Furthermore, the processes of change questionnaires used in this setting measure dietary behaviour and physical activity separately, although both aspects form part of weight management interventions. In this regard, the present paper describes stages and processes of change questionnaires that were developed by expert consensus and which are designed to be applied to the weight management setting.

Firstly, a rigorous process of item refinement and a crossvalidation analysis of the P-Weight questionnaire identified four processes of change (EmR, WMA, EnR, WCE) implied in weight management, that measures a person's readiness both to diet and to engage in physical activity. Consequently, we proposed a four-correlated-factor model without distinguishing between experiential and behavioural processes. Lamb and Joshi [29] showed that the same four-factor structure is valid for dietary behaviour, these findings being supported by Prochaska et al. [31], who reported that only some of the initially proposed processes of change showed statistical changes along time. Other authors have previously highlighted the possibility of a simpler processes of change model $[22,32]$, given that second-order factors were not substantively meaningful compared with a correlated first-order factors model. In this regard, the present study found insufficient evidence to assert the presence of experiential and behavioural processes in weight management. For this to be the case, the empirical feasibility of the higher-order factors would need to be evidenced by the patterning of correlations among factors in the first-order model [56]. Consequently, processes belonging to the same second-order process (experiential or behavioural) should be more strongly correlated with one another than with the other processes, which was not the case in our data. Surprisingly, the analysis of correlations has not typically been included in the literature published to date, despite its important consequences as regards the model being proposed. Secondly, in the second-order factors model, experiential and behavioural processes were highly correlated $(\mathrm{r}=0.920)$, which indicates that a more parsimonious model can be obtained. As stated above, a correlation that exceeds 0.80 or 0.85 indicates poor discriminant validity, and the recommendation is then to obtain a more parsimonious solution
[56]. However, previous studies have supported the presence of higher-order factors, despite there being high correlations between the experiential and behavioural processes [21-23]. Consequently, the present results support the conclusion that a simpler model which does not include experiential and behavioural processes is the most suitable one for weight management, this being consistent with reports from other fields $[22,24,25,29]$.

Secondly, the reliability analysis of the P-Weight revealed adequate corrected item-total correlations and high internal consistency coefficients, both on the subscales and the total scale, thereby supporting the adequate psychometric properties of the questionnaire.

Thirdly, and as regards the relationship between stages and processes of change, the analysis showed that people at the PC stage use significantly fewer processes than do those at other stages, which again is in line with previous studies $[12,18]$. However, similar to the findings reported by Marshall and Biddle [33] for physical activity, the pattern of process use across stages appears to differ from the linear pattern proposed in smoking cessation. In agreement with DiClemente et al. [12] and Rosen [59], we found that the pattern in weight management showed a peak use of processes of change in the A stage and a slight decline in some processes (EmR and WCE) in the M stage. This pattern fitted a quadratic trend.

Finally, the adequate correlations between the processes of change scores and external criteria are evidence of the adequate convergent validity of the scale.

To sum up, the adequate properties of the Spanish version of the P-Weight support its application in TTM-based weight management interventions. As stated by Hankey et al. [60], motivational factors play an important role in weight management interventions. Indeed, there is evidence [61] for a relationship between a motivational intervention based on the TTM and the efforts made by patients to stabilise or lose weight, in this case, in terms of adherence rates. In this context, the availability of reliable and valid measures based on the TTM is a promising step forward. Consequently, tailoring weight management interventions according to a patient's motivational stage and use of processes would allow practitioners to employ different strategies and treatment approaches in order to facilitate the use of these processes and, hence, the patient's progress across the stages.

Finally, certain limitations related to the sampling procedure used in the present study have to be considered before applying the S-Weight and P-Weight to clinical settings. The present sample consisted of both normal-weight and overweight and obese patients. Consequently, the application of these questionnaires to different populations of overweight and obese people who are attempting to lose weight would provide a more accurate description of the psychometric properties of the P-Weight and the use of processes across the stages at different points in a weight management programme. 


\section{Acknowledgements}

We would like to specially thank A. Lecube from Hospital Vall d'Hebron for his help. Also, we would like to thank M. Antón, J.M. Peri, P. Flotats, M.A. Viloca, V. Moize, L. Loyola, M.A. Rifà, M. Masagué, and E. Niso for their collaboration in this study. This study was partially supported by grants 2009SGR822 from the 'Agència de Gestió d'Ajuts Universitaris i de Recerca, Generalitat de Catalunya' and PSI2009-07280 from Spain's 'Ministerio de Ciencia e Innovación'.

\section{Disclosure Statement}

The authors declare no conflict of interest.

\section{References}

1 WHO: Obesity, Preventing and Managing the Global Epidemic. Report of a WHO Consultation on Obesity. World Health Organization, Geneva, 2000.

2 Aranceta J, Pérez Rodrigo C, Serra Majem L, et al: Prevalencia de la obesidad en España: resultados del estudio SEEDO 2000. Med Clin (Barc) 2003;120:608-612.

$\checkmark 3$ Flegal KM, Carroll MD, Ogden CL, Curtin LR: Prevalence and trends in obesity among US adults, 1999-2008. JAMA 2010;303:235-241.

4 National Institutes of Health NH, Lung, and Blood Institute, and the North American Association for the Study of Obesity: Practical Guide to the Identification, Evaluation, and Treatment of Overweight and Obesity in Adults. Department of Health and Human Services, Public Health Service, Washington, DC, 2000.

5 Bautista-Castaño I, Molina-Cabrillana J, MontoyaAlonso JA, Serra-Majem L: Variables predictive of adherence to diet and physical activity recommendations in the treatment of obesity and overweight, in a group of Spanish subjects. Int J Obes 2004;28:697-705.

6 Schelling S, Munsch S, Meyer AH, Margraf J: Relationship between motivation for weight loss and dieting and binge eating in a representative population survey. Int J Eat Disord 2011;44:39-43.

7 Goldberg JH, Kiernan M: innovative techniques to address retention in a behavioral weight-loss trial. Health Educ Res 2005;20:439-447.

$>8$ West DS, DiLillo V, Bursac Z, Gore SA, Greene PG: Motivational interviewing improves weight loss in women with type 2 diabetes. Diabetes Care 2007:30:1081-1087.

-9 Prochaska JO, DiClemente CC: Stages and processes of self-change in smoking: toward an integrative model of change. J Consult Clin Psychol 1983;51:390-395.

10 Norcross JC, Krebs PM, Prochaska JO: Stages of change. J Clin Psychol 2011;67:143-154.

11 Seals JG: Integrating the transtheoretical model into the management of overweight and obese adults. J Am Acad Nurse Pract 2007;19:63-71.

12 DiClemente CC, Prochaska JO, Fairhurst SK, Velicer WF, Velasquez MM, Rossi JS: The processes of smoking cessation: an analysis of precontemplation, contemplation, and preparation stages of change. J Consult Clin Psychol 1991;59:295-304.

13 DiClemente CC, Prochaska JO: Processes and stages of self-change: coping and competence in smoking behavior change; in Shiffman S, Wills T (eds): Coping and Substance Abuse. San Diego, Academic Press, 1985, pp 319-343.

14 Prochaska J, DiClemente CC, Norcross JC: In search how people change. Am Psychol 1992;9:1102-1114.
15 Prochaska JO, DiClemente CC: Common processes of self-change in smoking, weight control, and psychological distress; in Shiffman S, Wills T (eds): Coping and Substance Abuse. San Diego, Academic Press, 1985, pp 345-363.

16 Prochaska JO, DiClemente CC: The Transtheoretical Approach: Crossing the Traditional Boundaries of Therapy. Krieger, Malabar, 1984.

17 Prochaska JO, Velicer WF, Guadagnoli E, Rossi JS, DiClemente CC: Patterns of change: dynamic typology applied to smoking cessation. Multivar Behav Res 1992;26:83-107.

18 Prochaka JO, Velicer WF, DiClemente CC, Fava J: Measuring processes of change: applications to the cessation of smoking. J Consult Clin Psychol 1988; 56:520-528.

19 O'Connor EA, Carbonari JP, DiClemente CC: Gender and smoking cessation: a factor structure comparison of processes of change. J Consult Clin Psychol 1996;64:130-138.

20 DiClemente CC, Carbonari JP, Addy RC, Velasquez MM: Alternate short forms of a processes of change scale for alcoholism treatment. Paper presented at the Fourth International Congress on Behavioral Medicine, 1996.

21 Freyer J, Bott K, Riedel J, et al: Psychometric properties of the 'Processes of Change' scale for alcohol misuse and its short form (POC-20). Addict Behav 2006;31:821-832.

22 Marcus BH, Rossi JS, Selby VC, Niaura RS, Abrams DB: The stages and processes of exercise adoption and maintenance in a worksite sample. Health Psychol 1992;11:386-395.

23 Nigg CR, Norman GJ, Rossi JS, Benisovich SV: Processes of exercise behavior change: redeveloping the scale. Ann Behav Med 1999;21:S79.

24 Belding MA, Iguchi MY, Lamb RJ, Lakin M, Terry $\mathrm{R}$ : Stages and processes of change among polydrug users in methadone maintenance treatment. Drug Alcohol Depend 1995;39:45-53.

25 Pruitt SL, McQueen A, Tiro JA, Rakowski W, DiClemente CC, Vernon SW: Construct validity of a mammography processes of change scale and invariance by stage of change. J Health Psychol 2009;15:64-74.

26 Jezewski MA, Finnell DS, Wu YWB, Meeker MA, Sessanna L, Lee J: Psychometric testing of four transtheoretical model questionnaires for the behavior, completing health care proxies. Res Nurs Health 2009;32:606-620.

27 Horwath CC: Applying the transtheoretical model to eating behaviour change: challenges and opportunities. Nutr Res Rev 1999;12:281-317.

28 Povey R, Conner M, Sparks P, James R, Sheperd $\mathrm{R}$ : A critical examination of the application of the Transtheoretical Model's stages of change to dietary behaviours. Health Educ Res 1999;14:641-651.
29 Lamb R, Joshi MS: The stage model and processes of change in dietary fat reduction. J Human Nutr Diet 1996;9:43-53.

30 Surís AM, Trapp MC, DiClemente CC, Cousins J: Application of the transtheoretical model of behavior change for obesity in Mexican American women. Addict Behav 1998;23:655-668.

31 Prochaska JO, Norcross JC, Fowler JL, Follick MJ, Abrams DB: Attendance and outcome in a worksite weight control program: processes and stages of change as process and predictor variables. Addict Behav 1992;17:35-45.

32 Rossi SR, Rossi JS, Rossi-DelPrete LM, Prochaska JO, Banspach SW, Carleton RA: A processes of change model for weight control for participants in community-based weight loss programs. Int J Addict 1994;29:161-177.

33 Marshall SJ, Biddle SJH: The transtheoretical model of behavior change: a meta-analysis of applications to physical activity and exercise. Ann Behav Med 2001;23:229-246.

34 Greene GW, Rossi SR: Stages of change for reducing dietary fat over 18 months. J Am Diet Ass 1998;98:529-534.

35 Andrés A, Saldaña C, Gómez-Benito J: Establishing the stages and processes of change for weight loss by consensus of experts. Obesity 2009;17:1717-1723.

36 Linstone H, Turnoff M: The Delphi Method: Techniques and Applications. Boston, Addison-Wesley Publishing, 1975.

37 Donovan RJ, Jones S, Holman CDAJ, Corti B: Assessing the reliability of a stages of change scale. Health Educ Res 1998; 13:285-291.

38 Bulley C, Donaghy M, Payne A, Mutrie N: A critical review of the validity of measuring stages of change in relation to exercise and moderate physical activity. Crit Publ Health 2007;17:17-30.

39 Garner DM: EDI-2 Eating disorders inventory. EDI-2 Inventario de trastornos de la conducta alimentaria. Madrid, TEA Ediciones SA, 1998.

40 Garner DM, Garfinkel PE: Eating Attitudes Test: an index of the symptoms of anorexia nervosa. Psychol Med 1979;9:273-279.

41 Castro J, Toro J, Salamero M, Guimerá E: The Eating Attitudes Test: validation of the Spanish version. PsycholAssess1991;7:175-190.

42 Guarino P, Lamping DL, Elbourne D, Carpenter J, Peduzzi P: A brief measure of perceived understanding of informed consent in a clinical trial was validated. J Clin Epidemiol 2006;59:608-614.

43 Streiner DL, Norman GR: Health Measurement Scales. A Practical Guide to Their Development and Use. Oxford, Oxford University Press, 2003.

44 Ware JE, Gandek B: for the IQOLA Project Group. Methods for testing data quality, scaling assumptions, and reliability: the IQOLA Project approach. J Clin Epidemiol 1998;51:945-952. 
45 Floyd FJ, Widaman KF: Factor analysis in the development and refinement of clinical assessment instruments. Psychol Assess 1995;7:286-299.

46 Kaiser HF: The application of electronic computers to factor analysis. Educ Psychol Meas 1960;20,141151.

47 Mardia KV: Measures of multivariate skewness and kurtosis with applications. Biometrika 1970;57 519-530.

48 Bentler PM: EQS 6 Structural Equations Program Manual. Multivariate Software, Encino, 2005.

49 Jöreskog KF, Sörbom D: LISREL VI: Analysis of Linear Structural Relationships by Maximum Likelihood, Instrumental Variables, and Least Square Methods. Morresville, Scientific Software Inc, 1986.

-50 Mulaik SA, James LR, Van Altine J, Bennett N, Lind S, Stilwell CD: Evaluation of goodness-of-fit indices for structural equation models. Psychol Bull 1989;105:430-445.
51 Bentler PM, Bonet DG: Significance tests and goodness of fit in the analysis of covariance structures. Psychol Bull 1980;88:588-606.

57 Prochaska JO, Velicer WF: The transtheoretical model of behaviour change. Am J Health Prom 1997;12:38-48.

52 Jackson DL, Gillaspy JA, Purc-Stephenson R: Reporting practices in confirmatory factor analysis: an overview and some recommendations. Psychol Methods 2009;14:6-23.

53 Hu LT, Bentler PM: Cutoff criteria for fit indexes in covariance structure analysis: Conventional criteria versus new alternatives. Struct Equ Modeling 1999;6:1-55.

54 Nunnally JC, Bernstein IH: Psychometric Theory, 3rd ed. New York, McGraw-Hill, 1994.

55 Schafer JL, Graham JW: Missing data: our view of the state of the art. Psychol Methods 2002;7:147-177.

56 Brown TA: Confirmatory Factor Analysis for Applied Research. New York, Guildford Press, 2006.
( Behav Modif 2002;26:223-273.

59 Rosen CS: Is the sequencing of change processes by stage consistent across health problems? A meta-analysis. Health Psychol 2000;19:593-604.

60 Hankey CR, Leslie WS, Lean MEJ: Why lose weight? Reasons for seeking weight loss by overweight but otherwise healthy men. In J Obes 2002;26:880-882.

61 Schelling S, Munsch S, Meyer AH, et al: Increasing the motivation for physical activity in obese patients. Int J Eat Disord 2009;42:130-138. 